\title{
Giant Cell Reparative Granuloma of the Sphenoid and Orbit: Case Report-Tripoli-Libya
}

\author{
Amal Elbahi ${ }^{1,2 *}$, Muffaq Lashhab ${ }^{1,3}$, Hamza Alshawish $^{3}$, Hesham ben khayal ${ }^{1,3}$ \\ ${ }^{1}$ Tripoli University, Libya \\ ${ }^{2}$ Tripoli Eye Hospital, Libya \\ ${ }^{3}$ Anwar Alsalam Clinic, Libya
}

*Corresponding author: Amal M Elbahi, Tripoli University, Libya

Received Date: July 19, 2021

Published Date: August 10, 2021

\begin{abstract}
This case describes a case of giant cell reparative granuloma(GCRG) of the sphenoid and orbit, which is rarely affect these locations .Our case is a 48 years old female, who presented with proptosis in her left eye; imaging demonstrated a large sphenoid mass affecting the lateral wall of the orbit which was resected via an intracrainial approach. Based on immunohistochemeistry stain, was proved to be a GCRG.
\end{abstract}

Keywords: Proptosis; Giant cell reparative granuloma; Sphenoid

\section{Case Report}

An 48-years-old female presented with acute protrusion of the Left eye and left-sided temple swelling. The swelling began three weeks prior to presentation. She has no other past medical illnesses and there was no history of trauma. Examination revealed normal visual acuity, a lesh nodules in her both eyes, and a 7 mm of exophthalmos of left eye, no obvious restriction of ocular movement, no optic disc swelling, and, had no skin manifestations. Orbital and brain magnetic resonance imaging (MRI) with contrast and computed tomography (CT) scan was done (Figure 1 \& 2) which demonstrated a superotemporal mass of the left orbit and sphenidal region without intracranial extension (Figure 1 \& 2).
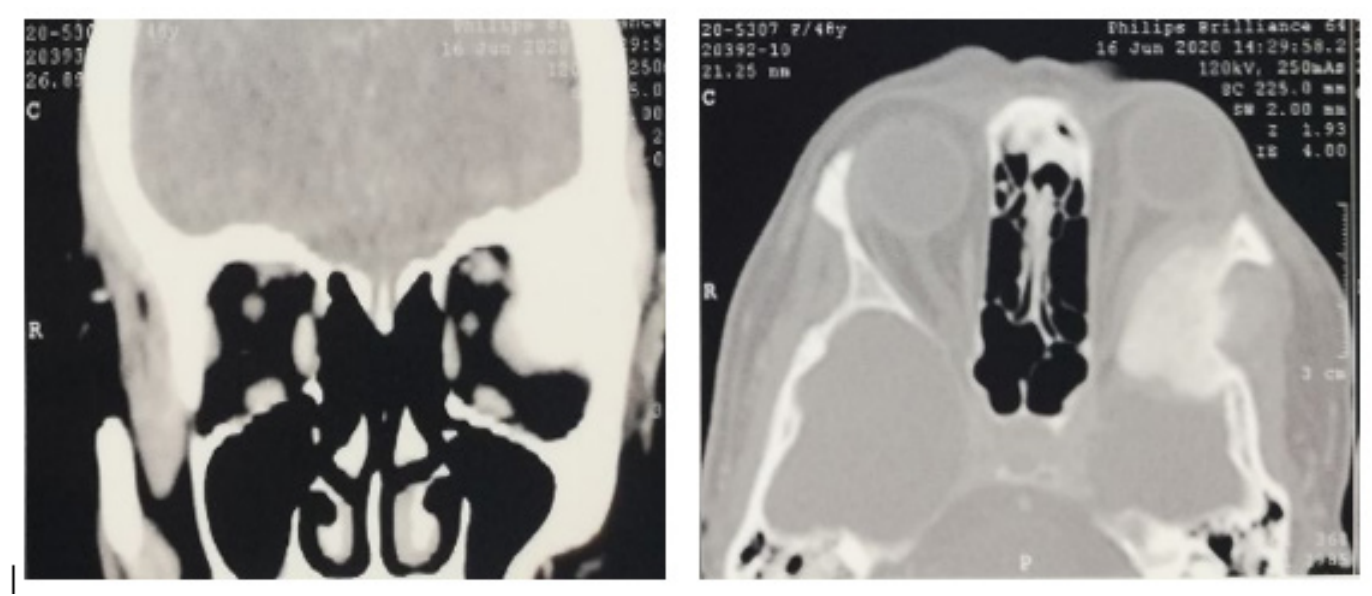

Figure 1: Coronal and Axial CT images with gadolinium shows a sphenoidal mass with contrast enhancement. 

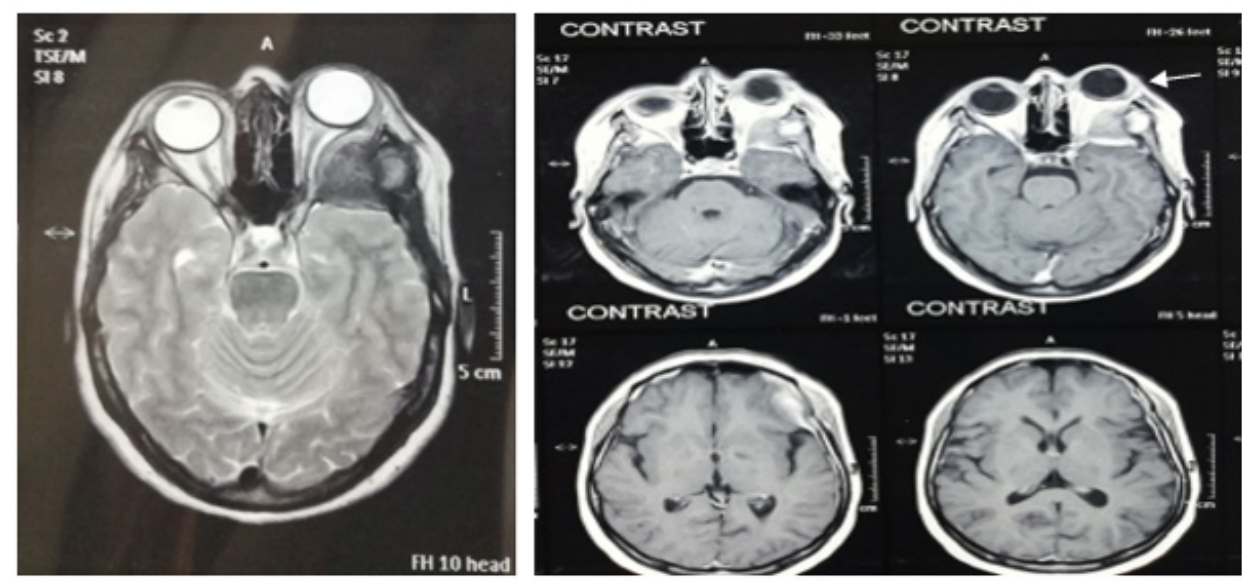

Figure 2: Axial MR images with gadolinium ; orbital compressing effect and eccentrically placed (arrows).

The patient underwent surgical intervention and histological examination revealed destructed bone tissue with diffuse replacement of the interstitial stroma of bone trabeculae and soft tissue by granuloma consist of gaint cells and histiocyte cells. Immunohistochemistry stain was CD68 positive, and an orbital mass was feature compatible with aggressive central gaint cell granuloma. The patient was then subjected to regular follow-up.

\section{Discussion}

Giant cell reparative granuloma is a rare fibro-osseous benign lesion, which spread locally and progress aggressively, so it makes these lesions behave as clinically malignant. These lesions have varied clinical presentation, according to their locations and the surrounding anatomical structures [1]. Lesions located in the tempro-orbital region can present as periorbital swelling, diplopia, proptosis, and facial deformity [2].

GCRG are most commonly described previously in the orbit in younger patients but can occur in all age groups [3]. Histologically, all GCRG lesions are composed of multinucleated giant cells unevenly distributed within a non-neoplastic fibrous stroma, admixed with areas of hemorrhage and reactive osteoid formation [4].

The differential diagnosis of GCRG includes, true giant cell tumor (GCT), aneurysmal bone cyst (ABC) and brown tumor of hyperparathyroidism [5]. Although these conditions are usually present a diagnostic challenge, nonspecific histologic and similar radiologic appearances can result in poor characterization of several of the rarer lesions. For example, radiologically, GCT and GCRG are indistinguishable. On CT, both usually appear as nonspecific lytic lesions. On MR imaging, most lesions show areas of low signal intensity on T1- and T2-weighted imaging, corresponding to the areas of fibrosis and/or hemosiderin. Both tumors enhance, with the degree of enhancement ranging from slight to strong [5]. The primary difference between the two is the prognosis. GCT has a higher incidence of recurrence and may undergo malignant transformation and metastasize. Meanwhile, GCRG has no metastasis or malignant transformation and surgery alone is the choice of treatment [6], so regular follow up is recommended.

\section{Acknowledgement}

None.

\section{Conflict of Interest}

No conflict of interest.

\section{References}

1. Magu S, Mathur SK, Gulati SP (2003) Giant cell reparative granuloma of the base of the skull presenting as a parapharingeal mass. Neurol India 51: $260-262$

2. Sood GC, Malik SRK, Gupta K, Kakar PK (1967) Reparative granuloma of the orbit causing unilateral proptosis. Am J Ophthalmol 63: 524-527.

3. Williams JC, Thorell WE, Treves JS (2000) Giant cell reparative granuloma of the petrous temporal bone: A case report and literature review. Skull Base Surg 10(2): 89-93.

4. Mercado GV, Shields CL, Gunduz K (1999) Giant cell reparative granuloma of the orbit. Am J Ophthalmol 127: 485-487.

5. Pherwani AA, Brooker D, Lacey B (2005) Giant cell reparative granuloma of the orbit. Ophthal Plast Recostr Surg 21(6): 463-465.

6. Aralasmak A, Aygun N, Westra WH, Yousem DM (2006) Giant cell reparative granuloma of the sphenoid bone. AJNR Am J Neuroradiol 27: $1675-1677$. 